\title{
Imprinted Nanostructures for Light Management in Crystalline Silicon Thin-Film Solar Cells on Glass
}

\author{
D. Eisenhauer, G. Köppel, K. Jäger, B. Rech, and C. Becker* \\ Helmholtz-Zentrum Berlin für Materialen und Energie GmbH, Kekuléstr. 5, 12489 Berlin, Germany \\ *christiane.becker@helmholtz-berlin.de
}

\begin{abstract}
We present various imprinted nanostructures for light management in liquid-phase crystallized silicon thin-film solar cells enabling both, increased $j_{\mathrm{sc}}$ by enhanced absorption and excellent electronic material-quality with $V_{\text {oc }}$ values above $640 \mathrm{mV}$.

OCIS codes: $000.2190,040.5350,110.4235$
\end{abstract}

\section{Introduction}

The crystallization of $5-40 \mu \mathrm{m}$ thin silicon ( $\mathrm{Si}$ ) films directly on a glass substrate is a promising approach that allows reduced absorber thicknesses and hence low material consumption for producing photovoltaic devices. Such silicon thin-film solar cells with $10 \mu \mathrm{m}$ thin absorbers prepared by liquid-phase crystallization (LPC) already yield wafer-equivalent morphologies, open-circuit voltages up to $650 \mathrm{mV} \mathrm{[1]} \mathrm{and} \mathrm{conversion} \mathrm{efficiencies} \mathrm{above} \mathrm{12 \%} \mathrm{[2].}$ However, incomplete light absorption, particularly due to optical losses at the glass-silicon interface, has been identified as one major limiting factor. Therefore, we developed a technology for advanced light management by combining the silicon liquid-phase crystallization approach with large-area $\left(5 \times 5 \mathrm{~cm}^{2}\right)$ nanoimprint-textured glass superstrates [3]. The main challenge of these nanostructured devices is to achieve simultaneously both, an excellent silicon material quality allowing open-circuit voltages well above $600 \mathrm{mV}$ and efficient light trapping.

Here, we summarize three different types of $750 \mathrm{~nm}$-periodic nanotextures implemented into liquid phase crystallized silicon thin-film solar cell devices including (1) pillar-like structures, (2) sinusoidal gratings corresponding to a pillar structure with smooth texture flanks and (3) morphologically flat but optically rough $\mathrm{SiO}_{x}$ $\mathrm{TiO}_{x}$-layer systems where the $\mathrm{TiO}_{x}$ fills the voids of the pillar structure. All three nanotextures are assessed with respect to light trapping properties as well as the material quality of the silicon absorber. The morphologically flat $\mathrm{SiO}_{x}-\mathrm{TiO}_{x}$-layer stack is found to overcome the trade-off between optical gain and nanotexture-caused electronic losses best: $8 \mu \mathrm{m}$ thin silicon solar cell test devices were fabricated exhibiting an excellent material quality with open-circuit voltage values above $640 \mathrm{mV}$ and a short-circuit current density of $23.3 \mathrm{~mA} \mathrm{~cm}^{-2}$, corresponding to a relative increase of $11 \%$ compared to $21.0 \mathrm{~mA} \mathrm{~cm}^{-2}$ of simultaneously processed optimized planar reference devices [4].

\section{Experimental}

Onto Corning Eagle XG glasses with a size of $5 \times 5 \mathrm{~cm}^{2}$ and a thickness of $1.1 \mathrm{~mm}$ a $250 \mathrm{~nm}$ thick $\mathrm{SiO}_{x}$ layer is deposited, which serves as diffusion barrier for glass impurities during subsequent high-temperature steps, particularly the silicon liquid-phase crystallization process. On top, a $750 \mathrm{~nm}$-periodic grating is nanoimprinted into a high-temperature stable, UV curable sol-gel resist that is based on silicon alcoxides either with pillar-like [nanostructure type (1) and (3)] or sinusoidal [nanostructure type (2)] features as shown in Fig. 1. Nanostructure types (1) and (2) are further coated by a $70 \mathrm{~nm} \mathrm{SiN}$ film for antireflection [5].

In case of nanostructure type (3) a titanium oxide precursor solution consisting of a mildly acidic solution of titanium isopropoxide in ethanol is spin-coated onto the nanoimprinted pillar-like surface. This leads to preferential filling of the voids and results in an almost smooth interface. The solvents are removed by thermal curing and a compact titanium oxide layer is formed. Finally, a $10 \mathrm{~nm}$ thin silicon oxide layer is sputtered on all three nanostructure types (1)-(3), serving as a passivation layer at the interface to the silicon absorber. More details can be found in references $[4,5]$. 


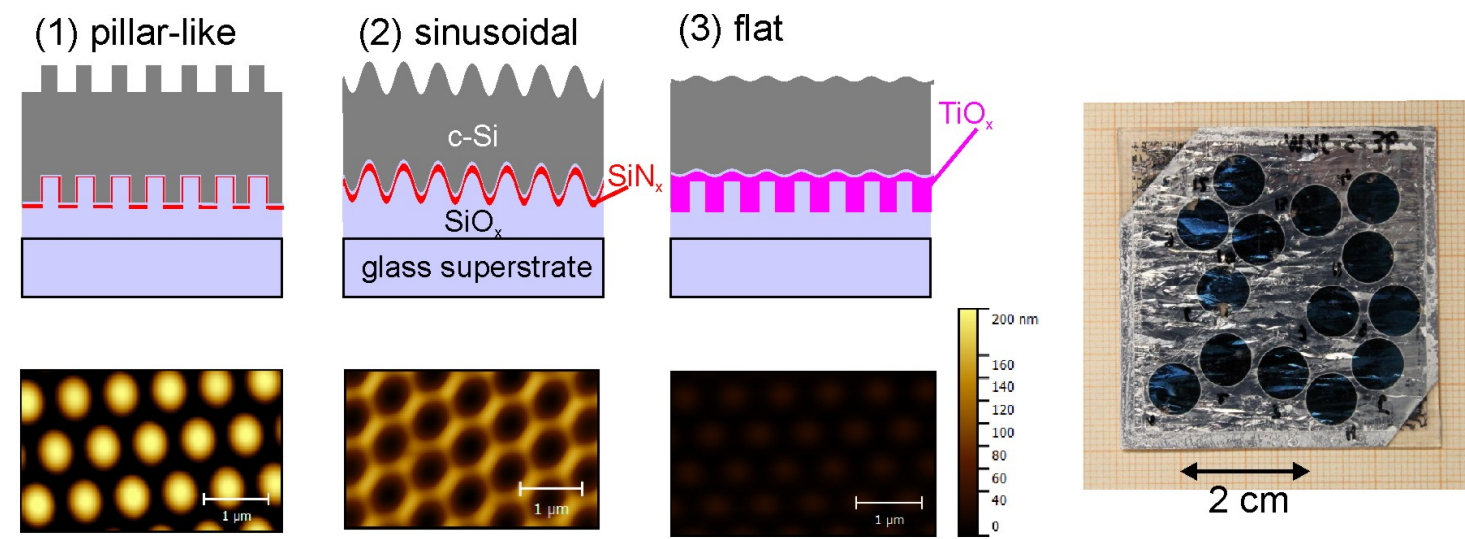

Fig. 1. Upper row: Illustration of the three types of $750 \mathrm{~nm}$-periodic nanostructured glass superstrates with (1) pillar-like, (2) sinusoidal and (3) morphologically flat $\mathrm{SiO}_{x}-\mathrm{TiO}_{x}$-layer stack used in liquid-phase crystallized silicon thin-film solar cells (texture height not to scale). Lower row: Corresponding atomic force microscopic images of the superstrates before silicon deposition.

Right side: Photograph of one $5 \times 5 \mathrm{~cm}^{2}$ large nanostructured crystalline silicon film with circular solar cell test devices.

Silicon layers of $8-10 \mu \mathrm{m}$ thickness are deposited onto these nanostructured superstrates by electron-beam evaporation at a temperature of $600^{\circ} \mathrm{C}$ resulting in nano-crystalline material. Prior to the laser crystallization process the samples of type (1) and (2) are capped with a $250 \mathrm{~nm}$ thick $\mathrm{SiO}_{x}$-layer enabling in a double-sided textured silicon layer. Then, the silicon is molten and recrystallized by scanning a line-shaped laser with $808 \mathrm{~nm}$ wavelength and a scanning velocity of $3 \mathrm{~mm} / \mathrm{s}$ across the samples, which results in crystal grains of up to centimeters in length and millimeters in width as can be seen at the right side of Fig. 1. In case of type (1) and (2), the $\mathrm{SiO}_{x}$ capping layer is removed by wet-chemical etching afterwards. Solar cell devices with an $n$-type absorber doping concentration of about $1 \times 10^{17} \mathrm{~cm}^{-3}$ and a-Si:H/c-Si heterojunction are prepared on all substrate types [1]. As reference, planar samples with a $\mathrm{SiO}_{x}(250 \mathrm{~nm}) / \operatorname{SiN}_{x}(70 \mathrm{~nm}) / \mathrm{SiO}_{x}(10 \mathrm{~nm})$ interlayer stack are used, which is designed such that it exhibits almost perfect anti-reflective and electronic properties for planar non-structured devices.

\section{Results and discussion}

Optical characteristics as well as solar cell parameters were measured in superstrate configuration, i.e. with the light impinging at the nanotexture via the glass superstrate. Figure 2 shows reflection and the external quantum efficiency spectra of LPC-Si thin-film solar cells on all three different types of nanotextured glass superstrates. With respect to optical performance all three types of nanotextures outperform the planar reference device, which already has an optimized antireflective $\mathrm{SiN}_{x} / \mathrm{SiO}_{x}$ layer stack (dashed lines), because reflection losses are significantly reduced. While the external quantum efficiency of the steeply textured pillar-like structure is strongly reduced compared to the planar reference, the smoother sinusoidal textures lead to partly higher, partly lower values. The flat $\mathrm{TiO}_{x}-\mathrm{SiO}_{x}$ structures, however, outperform the planar reference in almost the whole spectral range. 


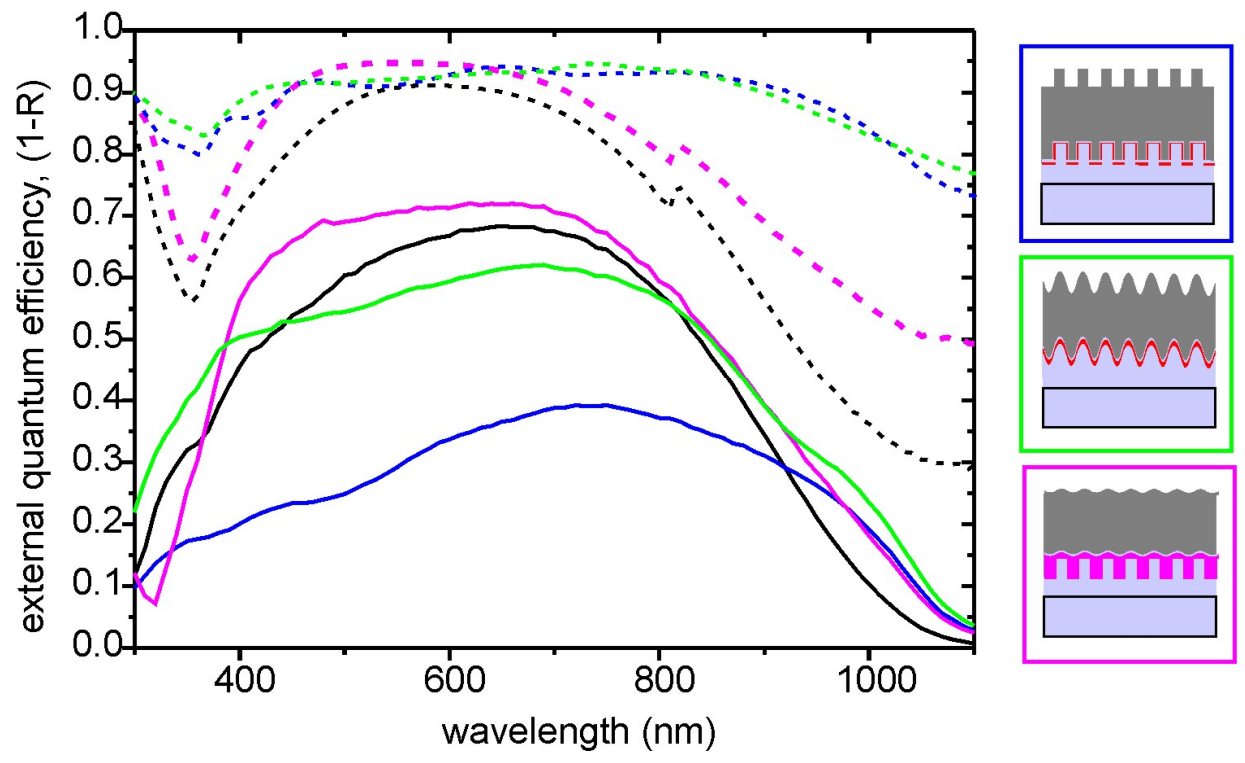

Fig. 2. Reflectance (here denoted as $1-R$, dashed lines) and external quantum efficiency (solid lines) of liquid phase crystallized silicon thinfilm solar cells on glass superstrates with pillar-like texture (blue), sinusoidal texture (green, from ref. [5]) and morphologically flat $\mathrm{SiO}_{x}-\mathrm{TiO}_{x}-$ layer system (magenta). The curves of the planar reference device with optimized antireflective $\mathrm{SiN}_{x} / \mathrm{SiO}_{x}$ layer stack are illustrated in black.

Short-circuit current densities $\left(j_{\mathrm{sc}}\right)$ are calculated from EQE measurements and maximum values are summarized in Table 1 together with maximum achieved open-circuit voltages $\left(V_{\mathrm{oc}}\right)$ obtained from Suns- $\mathrm{V}_{\mathrm{oc}}$ measurements. While pillar-like nanostructures exhibit a strongly reduced $V_{\text {oc }}$ and $j_{\text {sc }}$, sinusoidal and flat $\mathrm{TiO}_{x}-\mathrm{SiO}_{x}$ structures yield $V_{\text {oc }}$ values well above $600 \mathrm{mV}$. In case of the flat $\mathrm{TiO}_{x}-\mathrm{SiO}_{x}$ structures the optimized planar reference device is even outperformed.

Table. 1. Solar cell parameters, obtained by EQE and SunsVoc measurements, of laser crystallized silicon thin-film solar cells on different types of nanostructured glass superstrates.

\begin{tabular}{|c|c|c|}
\hline Sample type & $\max . \mathrm{V}_{\mathrm{oc}}[\mathrm{mV}]$ & $\max . j_{\mathrm{sc}}\left[\mathrm{mA} / \mathrm{cm}^{2}\right]$ \\
\hline (1) pillar-like & 492 & 12.6 \\
\hline (2) sinusoidal (from ref. [5]) & 618 & 20.9 \\
\hline (3) flat $\mathrm{SiO}_{x}-\mathrm{TiO}_{x}$ system & 649 & 23.3 \\
\hline planar reference & 636 & 21.0 \\
\hline
\end{tabular}

\section{Conclusion}

We presented a technology based on nanoimprint-lithography for the implementation of nanostructures for increased light in-coupling in $10 \mu \mathrm{m}$ thin liquid-phase crystallized silicon solar cells on glass superstrates. Three different types of $750 \mathrm{~nm}$-periodic nanostructures were analyzed with respect to optical and electronical solar cell performance: (1) pillar-like, (2) sinusoidal and (3) morphologically flat but optically rough $\mathrm{SiO}_{x}$ - $\mathrm{TiO}_{x}$-layer systems. The latter was found to overcome the trade-off between optical gain and nanotexture-caused electronic losses best, yielding reduced reflection losses compared to a planar reference device with already optimized antireflective layer stack, short-circuit current densities increased by $11 \%$ (relative) and open circuit voltages up to $649 \mathrm{mV}$. These results pave the way towards high-efficient silicon solar cells with strongly reduced absorber thickness, which is in line with the international technology roadmap of photovoltaics.

\section{References}

[1] J. Haschke, D. Amkreutz, L. Korte, F. Ruske, and B. Rech, "Towards wafer quality crystalline silicon thin-film solar cells on glass," Sol. Energy Mater. Sol. Cells 128, 190-197 (2014).

[2] T. Frijnts, S. Kühnapfel, S. Ring, O. Gabriel, S. Calnan, J. Haschke, B. Stannowski, B. Rech, and R. Schlatmann, "Analysis of photo-current potentials and losses in thin film crystalline silicon solar cells," Sol. Energy Mater. Sol. Cells 143, 457-466 (2015).

[3] C. Becker, V. Preidel, D. Amkreutz, J. Haschke, and B. Rech, "Double-side textured liquid phase crystallized silicon thin-film solar cells on imprinted glass,” Sol. Energy Mater. Sol. Cells 135, 2-7 (2015).

[4] D. Eisenhauer, G. Köppel, K. Jäger, D. Chen, O. Shargaieva, B. Rech, and C. Becker, Smooth anti-reflective three-dimensional texture for laser crystallized silicon thin-film solar cells on glass, submitted

[5] G. Köppel, B. Rech, and C. Becker, "Sinusoidal nanotextures for light management in silicon thin-film solar cells," Nanoscale 8, 8722-8728 (2016). 